\title{
The clinical utility of lurasidone in schizophrenia: patient considerations
}

\author{
This article was published in the following Dove Press journal: \\ Neuropsychiatric Disease and Treatment \\ 28 April 2015 \\ Number of times this article has been viewed
}

\section{Philip D Harvey}

'Department of Psychiatry and Behavioral Sciences, University of Miami, Miller School of Medicine, Miami, FL, USA; ${ }^{2}$ Bruce W Carter VA Medical Center, Miami, FL, USA
Correspondence: Philip D Harvey Department of Psychiatry and Behavioral Sciences, University of Miami, Miller School of Medicine, II 20 NW 14th Street, Miami, FL 33136, USA

Fax + I 305243 I619

Email philipdharveyl@cs.com

\begin{abstract}
Lurasidone is a novel antipsychotic agent approved for the treatment of schizophrenia in a number of countries including the United Kingdom, other European countries, the United States, and Canada. In addition to full antagonist activity at the dopamine $\mathrm{D}_{2}(\mathrm{Ki}, 1 \mathrm{nM})$ and serotonin $5-\mathrm{HT}_{2 \mathrm{~A}}(\mathrm{Ki}, 0.5 \mathrm{nM})$ receptors, the pharmacodynamic profile of lurasidone is notable for its high affinity for serotonin $5-\mathrm{HT}_{7}$ receptors $(0.5 \mathrm{nM})$ and its partial agonist activity at $5-\mathrm{HT}_{1 \mathrm{~A}}$ receptors $(\mathrm{Ki}, 6.4 \mathrm{nM}$ ). Long-term treatment of schizophrenia with lurasidone has been shown to reduce the risk of relapse in patients with schizophrenia. Lurasidone appears to be associated with minimal effects on body weight, and low risk for clinically meaningful alterations in glucose, lipids, or electrocardiography parameters. Evidence from two randomized trials also suggests improvement in functional capacity and cognitive functioning in people with schizophrenia. A significant evidence base supports the use of lurasidone as a promising agent for the treatment of schizophrenia.
\end{abstract}

Keywords: long-term treatment, antagonist, pharmacodynamic profile

\section{Introduction}

Lurasidone is a second-generation antipsychotic agent that initially received regulatory approval for the treatment of adults with schizophrenia in the United States in 2010. ${ }^{1,2}$ Lurasidone received marketing authorization for this indication by the European Medicines Agency in March 2014, and it has also been approved in Switzerland, Canada, the United Kingdom, and Australia. Additionally, lurasidone recently received US and Canadian regulatory approval for the treatment of adults with major depressive episodes associated with bipolar I disorder (bipolar depression), as either a monotherapy or as adjunctive therapy with lithium or valproate. Detailed systematic reviews of the overall efficacy, tolerability, safety, and place in therapy of lurasidone can be found elsewhere, ${ }^{3,4}$ including analyses of the number needed to treat (NNT) and number needed to harm (NNH).,

The published literature has used the US convention of describing the dose of lurasidone as the combined weight of the active drug moiety (lurasidone) plus the hydrochloride $(\mathrm{HCl})$ salt, with tablet strength expressed in multiples of $20 \mathrm{mg}$. In the European Union (EU), in Annex I: Summary of Product Characteristics, ${ }^{2}$ tablet strength refers to the weight of the active drug only, excluding the contribution of the $\mathrm{HCl}$ salt (Table 1 shows the dose equivalence). In the current review, the US dose convention will be utilized.

The purpose of this overview is to summarize the efficacy and safety of lurasidone for the treatment of schizophrenia, and to examine whether lurasidone has any special benefits that separate it from other atypical medications based on results from both short-term and longer-term controlled clinical trials. Relevant information regarding 
Table I Lurasidone dose equivalents in the EU, the UK, and the US

\begin{tabular}{ll}
\hline $\begin{array}{l}\text { EU/UK doses (mg, active } \\
\text { moiety) lurasidone }\end{array}$ & $\begin{array}{l}\text { US doses }(\mathbf{m g}, \mathbf{H C l ~ s a l t}) \\
\text { lurasidone }\end{array}$ \\
\hline 18.5 & 20 \\
37 & 40 \\
$56^{*}$ & 60 \\
74 & 80 \\
$111 *$ & 120 \\
$148^{*}$ & $160^{* *}$ \\
\hline
\end{tabular}

Notes: *Tablet strength not available in the EU/UK. **Tablet strength not available in the US.

Abbreviations: EU, European Union; UK, United Kingdom; US, United States.

switching and extension studies is reported, including functional and cognitive outcomes.

\section{Pharmacodynamics and pharmacokinetics}

Similar to most other second-generation antipsychotic agents, lurasidone is a full antagonist at the dopamine $\mathrm{D}_{2}$ and serotonin $5-\mathrm{HT}_{2 \mathrm{~A}}$ receptors, with binding affinities (Ki) of $1 \mathrm{nM}$ and $0.5 \mathrm{nM}$, respectively. In addition, lurasidone is distinguished by its high affinity for serotonin $5-\mathrm{HT}_{7}$ receptors $\left(0.5 \mathrm{nM}\right.$; comparable to the dopamine $\mathrm{D}_{2}$ and $5-\mathrm{HT}_{2 \mathrm{~A}}$ receptors) and by its partial agonist activity at $5-\mathrm{HT}_{1 \mathrm{~A}}$ receptors $(\mathrm{Ki}, 6.4 \mathrm{nM}){ }^{7}$ The serotonin $5-\mathrm{HT}_{7}$ receptor is a target of interest that may be associated with the potential for both procognitive and antidepressant effects. ${ }^{89}$ The $5-\mathrm{HT}_{1 \mathrm{~A}}$ receptor may have a role in the treatment of major depressive disorder ${ }^{10}$ and schizophrenia. ${ }^{11}$ Lurasidone lacks affinity for histamine $\mathrm{H}_{1}$ and muscarinic $\mathrm{M}_{1}$ receptors, which have important implications for low levels of sedation, reduced weight gain, and minimal interference with performance on cognitive and functional assessments.

The pharmacokinetic (PK) profile of lurasidone is consistent with once daily administration, with an elimination half-life of 18 hours. ${ }^{1}$ Mean $\mathrm{C}_{\max }$ and area under the curve for lurasidone were approximately threefold and twofold greater, respectively, in a comparison of administration with food versus fasting. ${ }^{12}$ Based on these data and on the results from clinical trials, it is recommended that lurasidone be taken once daily in the evening, with a meal or within 30 minutes after eating. ${ }^{1,2}$ Lurasidone absorption is independent of food fat content. ${ }^{12}$

Lurasidone is metabolized primarily via CYP3A4, and consequently its use is contraindicated in the presence of strong inducers and inhibitors of CYP3A4. Strong inhibitors among psychotropic medications include fluvoxamine and fluoxetine, and strong inducers include carbamazepine. In the presence of moderate inhibitors of CYP3A4, the recommended starting dose of lurasidone is $20 \mathrm{mg}$ /day rather than $40 \mathrm{mg} /$ day, and the highest recommended dose is $80 \mathrm{mg} /$ day rather than $160 \mathrm{mg} /$ day. Lurasidone does not affect the PK of other drugs including lithium, valproate, or agents that are metabolized by the CYP3A4 pathway. ${ }^{13}$

The examination of population subgroups based on sex, age, and race did not reveal any clear evidence of differential response to lurasidone; ${ }^{1,2}$ however, Asian subjects had 1.5-fold increased exposure to lurasidone when compared with Caucasian subjects. ${ }^{2}$ Clinical studies with lurasidone did not include sufficient numbers of patients aged 65 years and older to establish whether dose adjustment is necessary on the basis of age alone. In patients with moderate or severe renal or hepatic impairment, the recommended starting dose is $20 \mathrm{mg} / \mathrm{day}$, and the maximum dose should not exceed $80 \mathrm{mg} /$ day in moderate-to-severe renal impairment or moderate hepatic impairment, and $40 \mathrm{mg} /$ day in severe hepatic impairment.

\section{Efficacy in schizophrenia: acute treatment}

Based on a registration program that included five similarly designed 6-week, fixed-dose, placebo-controlled studies, ${ }^{14-18}$ lurasidone is approved for the treatment of schizophrenia within a dose range of 40-160 mg/day. Reductions in the Brief Psychiatric Rating Scale or Positive and Negative Syndrome Scale (PANSS) total scores were consistently greater for lurasidone compared with placebo across the approved dose range. A starting dose of $40 \mathrm{mg} /$ day has demonstrated significant efficacy; thus, no initial dose titration is necessary. Subsequent dose increases can be made based on clinician judgment, typically in increments of $40 \mathrm{mg}$ at approximately weekly intervals. Patients with suboptimal symptom control at lower doses of lurasidone may benefit from higher doses, as will be described. The NNT of lurasidone (versus placebo) for $\mathrm{a} \geq 30 \%$ reduction in the PANSS total score was $4(95 \%$ confidence interval [CI]: 3-5) for lurasidone $160 \mathrm{mg} /$ day compared to 6 (95\% CI: 5-10) at $40 \mathrm{mg} /$ day. ${ }^{5}$ This difference is potentially clinically significant and should be considered when dosing the medication.

The short-term effectiveness of lurasidone has also been evaluated in a study in which clinically stable, but symptomatic, outpatients with schizophrenia or schizoaffective disorder were switched from their current antipsychotic medication to lurasidone in a 6-week study that examined the efficacy and tolerability of three different dosing strategies (starting at $40 \mathrm{mg} /$ day for 2 weeks, versus starting at $80 \mathrm{mg} /$ day for 2 weeks, versus starting at $40 \mathrm{mg} /$ day for 
1 week followed by $80 \mathrm{mg} /$ day the 2 nd week). ${ }^{19}$ The primary outcome was time to treatment failure, defined as any occurrence of insufficient clinical response, exacerbation of disease, or discontinuation due to an adverse event. No clinically relevant differences were observed among the three groups in terms of efficacy or tolerability outcomes; treatment failure rates were also low for all three switch groups ( $~ 8 \%)$. Thus, patients who are switched to lurasidone can be started on a number of different dosing regimens with adjustment based on both early clinical response and tolerability.

At the present time, there have been no formal studies of first-episode or geriatric patients with schizophrenia and a pediatric study is still in process. It is not possible to make clear statements about sex differences in treatment response, but male and female patients have participated in all clinical trials.

\section{Efficacy in schizophrenia: long-term treatment}

Longer-term data for lurasidone in patients with schizophrenia are available based on randomized double-blind, 12-month trials that include comparisons with risperidone, in a safety study, ${ }^{20}$ and quetiapine extended-release (XR), in a double-blind extension to one of the short-term pivotal trials. ${ }^{21}$ In the risperidone comparator study, treatment with lurasidone was associated with comparable improvement in efficacy, with similar relapse rates at 12 months. In the quetiapine XR comparator study, lurasidone was noninferior to quetiapine XR in risk for relapse. At 12 months, treatment with lurasidone (modal daily dose $120 \mathrm{mg}$ ) was associated with a significantly greater improvement in PANSS total score compared with quetiapine XR (modal daily dose $600 \mathrm{mg}$ ), a nonsignificantly lower risk of relapse $(23.7 \%$ versus $33.6 \%$, respectively; $P=0.280$ ), significantly lower risk of rehospitalization at 12 months $(9.8 \%$ versus $23.1 \%$, respectively; logrank $P=0.049$ ), and significantly higher rates of attainment of remission (61.9\% versus $46.3 \%$, respectively; $P=0.043$ ). In the same study, a computerized cognitive battery (CogState) was administered at randomization and repeated at the end of 6 weeks of acute double-blind treatment, as well as after 3 months and 6 months of double-blind extension treatment. At all postrandomization time points, treatment with lurasidone at $160 \mathrm{mg}$ /day was associated with significantly greater improvement in cognition compared with placebo and quetiapine XR, with a moderate effect size. ${ }^{22}$ Further, improvements in a performance-based measure of functional capacity were detected in all active treatment groups and improvements in functional capacity were correlated with cognitive improvements. The specific mechanism of action of these benefits are not necessarily clear, as sedation from quetiapine XR could lead to poor cognitive performance, as much as the beneficial properties of lurasidone could lead to cognitive benefits.

These results are similar to those of a previous comparative study of lurasidone and ziprasidone, ${ }^{23}$ another atypical antipsychotic approved in several countries, including the US, for the treatment of schizophrenia. Conducted during the early development phases of lurasidone, this study was a short-term, double-blind, randomized head-to-head comparison of lurasidone versus ziprasidone in generally clinically stable outpatients with schizophrenia. ${ }^{23}$ At the time of this study, no US patients had ever been exposed to the drug. Patients were selected for being naïve to treatment with ziprasidone as well. A 3-week randomized trial examined changes in performance on a neuropsychological assessment consisting of most of the tests in the widely used Measurement and Treatment Research to Improve Cognition in Schizophrenia (MATRICS) Consensus Cognitive Battery $\left(\mathrm{MCCB}^{24}\right)$ and an interview-based assessment of cognitive functioning, the Schizophrenia Cognition Rating Scale $\left(\mathrm{SCoRS}^{25}\right)$, which allows for the detailed evaluation of both patient-reported and informant-reported cognitive functioning. Developed in response to the US Food and Drug Administration's requirement that any study examining the cognitive benefits of a pharmacological treatment also show concurrent evidence of meaningfulness of benefit, the SCoRS consists of questions about the patient's ability to manage cognitively demanding, functionally relevant, everyday tasks such as conversations, watching television, and using electronic devices.

The study found that lurasidone was associated with improvements on neuropsychological tests that were generally consistent with practice effects. There was one exception: processing speed, which improved more substantially and manifested a relatively greater improvement with lurasidone than that seen with ziprasidone. However, improvements seen with lurasidone on the SCoRS were double the size of improvements on the neuropsychological assessments and nearly significantly $(P<0.057)$ larger than the improvements associated with ziprasidone. These results cannot be attributed to practice effects, given that the SCoRS is an interview, not a performance-based measure. Furthermore, the fact that the differential effects of lurasidone and ziprasidone were nearly significant argues against a generalized bias effect ion rating the SCoRS, because the lurasidone effects were clearly larger. Again, the lack of clear improvement from baseline 
in this study on the neuropsychological tests suggests that cognitive improvements with lurasidone are not necessarily generalizable across all assessment strategies.

\section{Long-term effectiveness}

The long-term effectiveness of lurasidone in the treatment of schizophrenia has also been evaluated in two open-label extension studies. In the first, ${ }^{26}$ a 6-month extension of the switch study summarized earlier, the mean PANSS total score continued to show improvement. Moreover, low rates were observed for both psychiatric emergency service utilization (mean, $0.8 \%$ per month), and for contact with the criminal justice system (mean, $1.8 \%$ per month). ${ }^{26}$ In a second open-label extension study in which patients received 6 months of treatment with lurasidone, ${ }^{27}$ antipsychotic efficacy was maintained, with further reduction observed in mean PANSS total scores, in patients who had initially received lurasidone, olanzapine, or placebo during the acute treatment phase.

Preliminary results of a double-blind, randomized withdrawal study examining the maintenance of efficacy of lurasidone treatment in patients with chronic schizophrenia have been presented. ${ }^{28}$ Patients experiencing an acute exacerbation of schizophrenia received flexible doses of lurasidone (40 mg/day or $80 \mathrm{mg} /$ day) during a 12- to 24-week open-label stabilization phase. Those who maintained clinical stability for $\geq 12$ weeks entered a 28 -week, double-blind withdrawal phase and were randomized to receive either lurasidone, at the same dose they were receiving at completion of the stabilization phase, or placebo. Lurasidone significantly delayed time to relapse compared with placebo (log-rank $P=0.039$ ), and was associated with a $34 \%$ reduction in risk of relapse (Cox proportional hazard model ratio [95\% $\mathrm{CI}$ ], 0.66 [0.45-0.98]; $P=0.041$ ). All of the long- and short-term studies to date are presented in Figure 1.

\section{Dose escalation in nonresponders}

Although lurasidone is approved at doses up to $160 \mathrm{mg} /$ day with a favorable NNT for the higher dose for clinical response, it was unclear as to whether dose increases led to superior efficacy in individual patients. In consequence, a dose escalation in early nonresponder study was recently completed. ${ }^{29}$ In this study, 198 acutely psychotic patients were randomized to treatment with lurasidone $80 \mathrm{mg} /$ day, with 101 patients randomized to lurasidone $20 \mathrm{mg}$ /day in order to evaluate a potentially ineffective dose, and another 112 cases randomized to placebo. Patients were re-evaluated for clinical response at week 2 ; in the lurasidone $80 \mathrm{mg}$ arm, early responders (defined as a $\geq 20 \%$ reduction in PANSS scores) continued on treatment with lurasidone and early nonresponders ( $<20 \%$ response) were either randomized to stay on $80 \mathrm{mg} /$ day or to be increased to $160 \mathrm{mg} /$ day.

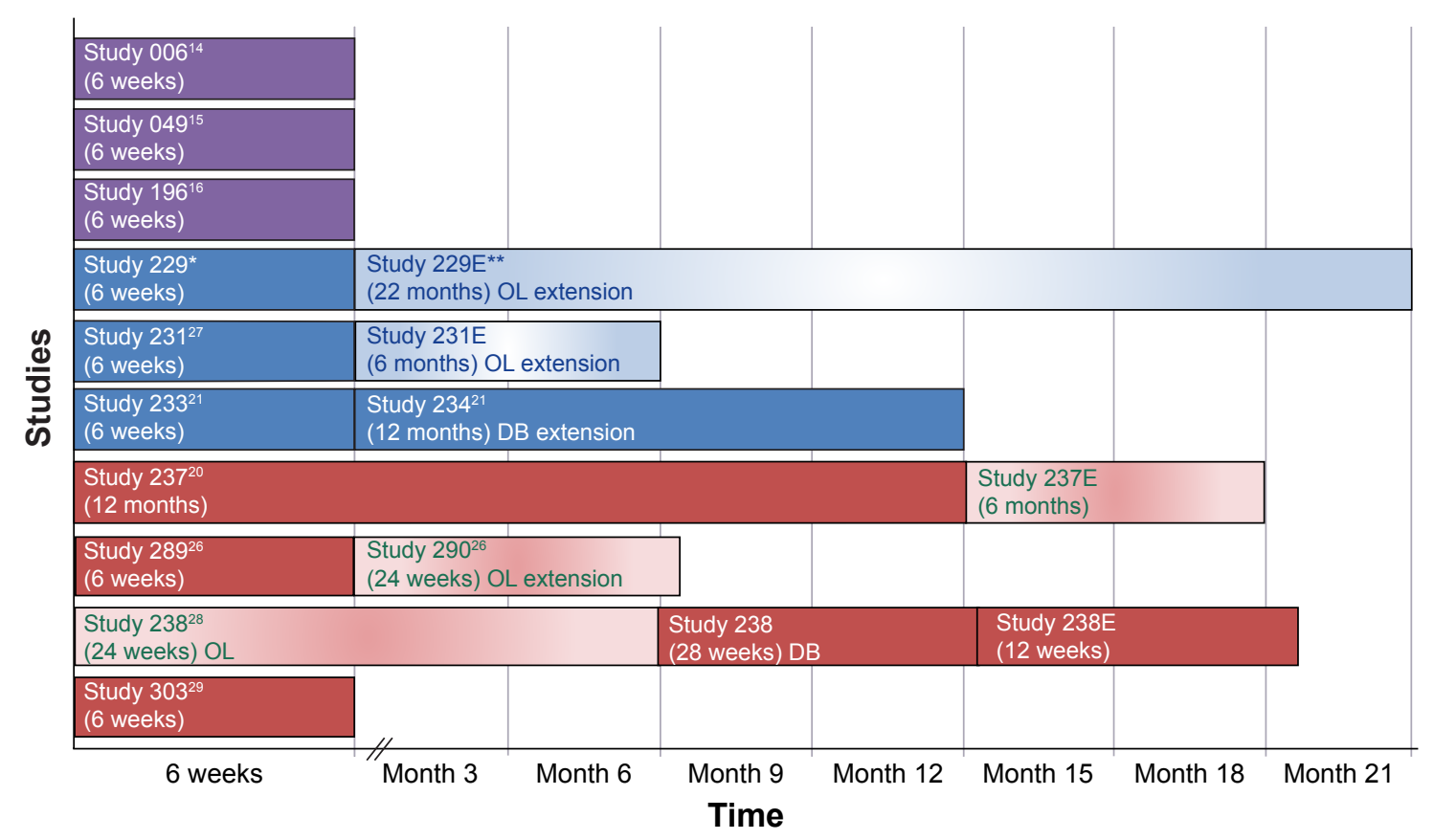

Figure I Summary of lurasidone schizophrenia clinical trials.

Notes: Study 049 was the only study with negative results for currently used doses. *Study 229 and **Study $229 \mathrm{E}$ were conducted by Sunovion Pharmaceuticals Inc., Marlborough, MA, USA.

Abbreviations: OL, Open-label; DB, Double-blind. 
The results of the study found that lurasidone $20 \mathrm{mg} /$ day was not effective and did not separate from placebo (the placebo change was 14.5 PANSS points versus 17.6 points in the lurasidone $20 \mathrm{mg}$ /day group). Patients with an early response to lurasidone $80 \mathrm{mg}$ /day manifested a 6-week response of 32 points $(P<0.001$ versus placebo). Lurasidone early nonresponders who stayed on lurasidone $80 \mathrm{mg} /$ day for the entire 6 weeks did not separate from placebo, changing by 14.1 points on the PANSS, while those patients who were switched to lurasidone $160 \mathrm{mg} /$ day after 2 weeks manifested a cumulative response of 21.8 PANSS points, separating from placebo at $P<0.05$.

This study has several clinical implications for patients. Early nonresponse suggests a need for rapid up-titration of the dose in order to obtain clinical response if it is not relatively immediate, as staying and waiting for a response on $80 \mathrm{mg}$ /day after early nonresponse was fruitless. The $20 \mathrm{mg}$ dose of lurasidone did not demonstrate efficacy and the results suggest that this would also be a fruitless starting dose regardless of tolerability issues. The NNT statistics are quite robust for early responders to $80 \mathrm{mg} /$ day at $\mathrm{NNT}=3$, with the combined early responder $(80 \mathrm{mg}$ ) and later responder (80-160 mg/day) showing an NNT of 4. Thus, treatment with lurasidone suggests that a rapid up-titration of lurasidone to $160 \mathrm{mg}$ /day in the face of early nonresponse is likely to be clinically useful. Further, the randomized pivotal trials examining $160 \mathrm{mg}$ /day of lurasidone suggested that a 3-day up-titration to $160 \mathrm{mg}$ /day at the outset of treatment was sufficient and that side effects did not differentiate substantially between $160 \mathrm{mg} /$ day and $80 \mathrm{mg} /$ day in the head-to-head trials.

\section{Tolerability and safety}

Commonly observed adverse reactions in short-term trials in schizophrenia (incidence on lurasidone $\geq 5 \%$ and twofold greater than placebo) were somnolence $(17 \%$ versus $7 \%$, respectively; $\mathrm{NNH}=10)$, akathisia ( $13 \%$ versus $3 \%$, respectively; $\mathrm{NNH}=10)$, nausea ( $10 \%$ versus $5 \%$, respectively; $\mathrm{NNH}=20)$, and Parkinsonism (10\% versus 5\%, respectively; $\mathrm{NNH}=20) .{ }^{1}$ Akathisia and extrapyramidal symptoms appear to be dose-related within the dose range of $20-120 \mathrm{mg} /$ day. ${ }^{1}$ The frequency of akathisia in patients with schizophrenia was $5.6 \%$ for $20 \mathrm{mg} /$ day, $10.7 \%$ for $40 \mathrm{mg} /$ day, $12.3 \%$ for $80 \mathrm{mg} /$ day, and $22.0 \%$ for $120 \mathrm{mg} /$ day. In a study where lurasidone was administered in the evening, ${ }^{18}$ akathisia was reported by $7.4 \%$ of patients receiving lurasidone $160 \mathrm{mg} / \mathrm{day}$. It is possible that evening dose administration is associated with more favorable tolerability overall relative to morning dosing. Adverse event frequencies (including movement disorders) reported in the bipolar depression program, where lurasidone was dosed at night in all studies, were generally lower than those observed in patients with schizophrenia. ${ }^{1}$ The mean change in weight observed across 6-week trials in schizophrenia was $+0.43 \mathrm{~kg}$ for lurasidone versus $-0.02 \mathrm{~kg}$ for placebo. In contrast, the mean change in weight was $+4.15 \mathrm{~kg}$ for olanzapine and $+2.09 \mathrm{~kg}$ for quetiapine XR in 6-week trials where these agents served as active controls. ${ }^{1,17,18}$ In 6-week trials, the proportion of patients with a clinically meaningful ( $\geq 7 \%$ ) endpoint increase in body weight was $4.8 \%$ for lurasidone versus $3.3 \%$ for placebo ( $\mathrm{NNH}=67$; not significant). ${ }^{1}$ In contrast, the proportion of patients with clinically significant weight gain during short-term treatment in one comparator study with olanzapine (versus placebo) was $34 \%$ versus $7 \%$, respectively $(\mathrm{NNH}=4) ;{ }^{17}$ and the proportion of patients with clinically significant weight gain in a second comparator study with quetiapine XR (versus placebo) was $15 \%$ versus $3 \%(\mathrm{NNH}=8) .{ }^{18}$ The proportion of patients with clinically significant weight gain on lurasidone was similar to the rate for placebo in both comparator studies $(\mathrm{NNH}>55) .{ }^{17,18}$ Longer-term studies for lurasidone are consistent with shortterm findings regarding changes in body weight; in a longterm study, ${ }^{2}$ lurasidone was associated with a mean change in weight of $+0.73 \mathrm{~kg}$ at month 12 compared with $+1.23 \mathrm{~kg}$ on quetiapine XR. Thus, quetiapine XR patients were quite likely to gain weight, with one in eight manifesting clinically significant weight gain. Lurasidone appeared as close to weight neutral as has ever been seen previously.

The short-term effect of lurasidone on metabolic variables appears minimal. ${ }^{1}$ In pooled short-term (6-week) clinical trials, the mean last observation carried forward endpoint change in total fasting cholesterol was $-1.7 \mathrm{mg} / \mathrm{dL}$ for lurasidone and $-3.2 \mathrm{ng} / \mathrm{dL}$ for placebo. ${ }^{30}$ The mean endpoint change in fasting triglycerides was $+3.0 \mathrm{ng} / \mathrm{dL}$ for lurasidone and +6.0 $\mathrm{ng} / \mathrm{dL}$ for placebo. The mean endpoint change in fasting glucose was $+1.0 \mathrm{ng} / \mathrm{dL}$ for lurasidone and $+1.8 \mathrm{ng} / \mathrm{dL}$ for placebo. Long-term data regarding metabolic outcomes extending out to 12 months are consistent with the short-term data. ${ }^{1,30}$ In long-term studies, ${ }^{26}$ the mean last observation carried forward endpoint change on lurasidone was $-0.02 \mathrm{ng} / \mathrm{dL}$ for total fasting cholesterol, $-6.7 \mathrm{ng} / \mathrm{dL}$ for fasting triglycerides, and $-0.3 \mathrm{ng} / \mathrm{dL}$ for fasting glucose.

A moderate dose-dependent increase in prolactin was observed in patients treated with lurasidone, with more pronounced effects in female than in male patients; however, the increase was lower than what is observed with risperidone and haloperidol. In a randomized 12-month double-blind 
safety study comparing lurasidone with risperidone, the mean change from baseline to endpoint in the serum prolactin levels in men was $+2.51 \mathrm{ng} / \mathrm{mL}$ for lurasidone and $+9.45 \mathrm{ng} / \mathrm{mL}$ for risperidone, and in women, $+5.16 \mathrm{ng} / \mathrm{mL}$ for lurasidone and $+33.90 \mathrm{ng} / \mathrm{mL}$ for risperidone. ${ }^{20}$

Serial electrocardiograms during short-term and longterm trials indicate that lurasidone, at doses as high as $558 \mathrm{mg} /$ day, does not have a clinically meaningful impact on the QT interval. ${ }^{1}$ This is an important advantage for this treatment and one that separates it from several other antipsychotic medications.

\section{Somnolence}

With the nearly complete absence of histamine $\mathrm{H}_{1}$ binding seen with lurasidone sedation, somnolence and weight gain should be lower than for drugs with higher levels of binding. As noted earlier, weight gain was greater in quetiapine XR patients treated in the pivotal head-to-head trials compared to lurasidone. However, an even greater impact was seen for somnolence. During the 6-week acute phase study, patients treated with lurasidone manifested improvements in sleepiness at both doses administered, with similar improvements in placebo-treated patients. ${ }^{31}$ In contrast, quetiapine XR patients worsened significantly from baseline in the Epworth Sleepiness Scale, a self-reported measure of daytime sleepiness. Assessments were conducted at baseline prior to randomization and repeated at weeks 3 and 6 of the clinical trial. Quetiapine XR was associated with worsening compared to placebo on 5/8 items and worsening compared to lurasidone on $6 / 8$ items. Importantly, the largest simple difference between lurasidone treatment and quetiapine XR was the report on the part of the quetiapine patients that they were likely to fall asleep in a car when stopped in traffic. ${ }^{31}$

There are obvious safety issues associated with this potential side effect, and with daytime sleepiness in general. Further, there was a direct correlation between worsening in scores on functional capacity measures and sleepiness in quetiapine XR patients, and the reduced cognitive benefit for quetiapine XR compared to lurasidone was mediated by worsening in sleepiness in the quetiapine XR group.

\section{Conclusion}

Lurasidone represents a new addition for the treatment of serious mental disorders. Lurasidone has demonstrated efficacy in the treatment of schizophrenia, within the dose range of 40-160 mg/day, with clearly defined lower boundary ineffective doses. Treatment with lurasidone appears to be associated with minimal effects on body weight and a lower risk for clinically meaningful alterations in glucose, lipids, or electrocardiography (ECG) parameters, as well as less sleepiness than comparator medicines. ${ }^{31}$ Lurasidone's combination of efficacy in schizophrenia with minimal metabolic disturbance, as well as little effect on movement disorders and prolactin, represents a potentially important clinical advancement. Clearly, this medication appears to have advantages over conventional medications and a number of atypical medications as well.

The results from a large-scale meta-analysis by Leucht et $\mathrm{al}^{32}$ are quite consistent with the information presented in this review. In that analysis, lurasidone had the lowest risk for ECG abnormalities; it also demonstrated efficacy in the top half of medications, and the weight gain risk was among the lowest of the currently available treatments. From the patient's perspective, it seems reasonable to suggest that this medication represents the best current trade-off between efficacy and side effect burden. Further, the potential for cognitive enhancement with lurasidone, a finding that has been partially replicated across studies conducted by the sponsor, could be an advantage as well.

\section{Disclosure}

In the past 12 months, Dr Harvey was a consultant for Boehringer Ingelheim; Forest Laboratories, Inc; FORUM Pharmaceuticals Inc; Genentech, Inc; Lundbeck; Otsuka Holdings Co, Ltd; Hoffman-La Roche Ltd; Sanofi; Sunovion Pharmaceuticals, Inc; and Takeda Pharmaceutical Company Limited. The author reports no other conflicts of interest in this work.

\section{References}

1. Latuda ${ }^{\circledR}$ (lurasidone $\mathrm{HCl}$ ) tablets [package insert]. Marlborough, MA: Sunovion Pharmaceuticals Inc.; 2013. Available from: http://www.latuda. com/LatudaPrescribingInformation.pdf. Accessed March 25, 2015.

2. European Medicines Agency. Annex I: Summary of Product Characteristics. London, UK: European Medicines Agency; 2014. Available from: http://www.ema.europa.eu/docs/en_GB/document_library/ EPAR_-_Product_Information/human/002713/WC500164683.pdf. Accessed March 25, 2015.

3. Citrome L. Lurasidone for schizophrenia: a review of the efficacy and safety profile for this newly approved second-generation antipsychotic. Int J Clin Pract. 2011;65(2):189-210.

4. Citrome L. Lurasidone in schizophrenia: new information about dosage and place in therapy. Adv Ther. 2012;29(10):815-825.

5. Citrome L. Lurasidone for the acute treatment of adults with schizophrenia: what is the number needed to treat, number needed to harm, and likelihood to be helped or harmed? Clin Schizophr Relat Psychoses. 2012;6(2):76-85

6. Citrome L, Ketter TA, Cucchiaro J, Loebel A. Clinical assessment of lurasidone benefit and risk in the treatment of bipolar I depression using number needed to treat, number needed to harm, and likelihood to be helped or harmed. $J$ Affect Disord. 2014;155:20-27. 
7. Ishibashi T, Horisawa T, Tokuda K, et al. Pharmacological profile of lurasidone, a novel antipsychotic agent with potent 5-hydroxytryptamine 7 (5-HT7) and 5-HT1A receptor activity. J Pharmacol Exp Ther. 2010; 334(1):171-181.

8. Horiguchi M, Huang M, Meltzer HY. The role of 5-hydroxytryptamine 7 receptors in the phencyclidine-induced novel object recognition deficit in rats. J Pharmacol Exp Ther. 2011;338(2):605-614.

9. Cates LN, Roberts AJ, Huitron-Resendiz S, Hedlund PB. Effects of lurasidone in behavioral models of depression. Role of the 5-HT receptor subtype. Neuropharmacology. 2013;70:211-217.

10. Blier P, Ward NM. Is there a role for 5-HT1A agonists in the treatment of depression? Biol Psychiatry. 2003;53(3):193-203.

11. Ohno Y. Therapeutic role of 5-HT1A receptors in the treatment of schizophrenia and Parkinson's disease. CNS Neurosci Ther. 2011;17(1): 58-65.

12. Preskorn S, Ereshefsky L, Chiu YY, Poola N, Loebel A. Effect of food on the pharmacokinetics of lurasidone: results of two randomized, open-label, crossover studies. Hum Psychopharmacol. 2013;28(5): 495-505.

13. Chiu YY, Ereshefsky L, Preskorn SH, Poola N, Loebel A. Lurasidone drug-drug interaction studies: a comprehensive review. Drug Metabol Drug Interact. 2014;29(3):191-202.

14. Ogasa M, Kimura T, Nakamura M, Guarino J. Lurasidone in the treatment of schizophrenia: a 6-week, placebo-controlled study. Psychopharmacology (Berl). 2013;225(3):519-530.

15. Nakamura M, Ogasa M, Guarino J, et al. Lurasidone in the treatment of acute schizophrenia: a double-blind, placebo-controlled trial. J Clin Psychiatry. 2009;70(6):829-836.

16. Nasrallah HA, Silva R, Phillips D, et al. Lurasidone for the treatment of acutely psychotic patients with schizophrenia: a 6-week, randomized, placebo-controlled study. J Psychiatr Res. 2013;47(5):670-677.

17. Meltzer HY, Cucchiaro J, Silva R, et al. Lurasidone in the treatment of schizophrenia: a randomized, double-blind, placebo- and olanzapinecontrolled study. Am J Psychiatry. 2011;168(9):957-967.

18. Loebel A, Cucchiaro J, Sarma K, et al. Efficacy and safety of lurasidone $80 \mathrm{mg} /$ day and $160 \mathrm{mg} /$ day in the treatment of schizophrenia: a randomized, double-blind, placebo- and active-controlled trial. Schizophr Res. 2013;145(1-3):101-109.

19. McEvoy JP, Citrome L, Hernandez D, et al. Effectiveness of lurasidone in patients with schizophrenia or schizoaffective disorder switched from other antipsychotics: a randomized, 6-week, open-label study. J Clin Psychiatry. 2013;74(2):170-179.

20. Citrome L, Cucchiaro J, Sarma K, et al. Long-term safety and tolerability of lurasidone in schizophrenia: a 12-month, double-blind, activecontrolled study. Int Clin Psychopharmacol. 2012;27(3):165-176.

21. Loebel A, Cucchiaro J, Xu J, Sarma K, Pikalov A, Kane JM. Effectiveness of lurasidone vs quetiapine XR for relapse prevention in schizophrenia: a 12-month, double-blind, noninferiority study. Schizophr Res. 2013;147(1):95-102.
22. Harvey PD, Siu CO, Hsu J, Cucchiaro J, Maruff P, Loebel A. Effect of lurasidone on neurocognitive performance in patients with schizophrenia: a short-term placebo- and active-controlled study followed by a 6-month double-blind extension. Eur Neuropsychopharmacol. 2013; 23(11):1373-1382.

23. Harvey PD, Ogasa M, Cucchiaro J, Loebel A, Keefe RS. Performance and interview-based assessments of cognitive change in a randomized, double-blind comparison of lurasidone vs ziprasidone. Schizophr Res. 2011;127(1-3):188-194.

24. Nuechterlein KH, Green MF, Kern RS, et al. The MATRICS Consensus Cognitive Battery, part 1: test selection, reliability, and validity. Am J Psychiatry. 2008;165(2):203-213.

25. Keefe RS, Poe M, Walker TM, Kang JW, Harvey PD. The Schizophrenia Cognition Rating Scale: an interview-based assessment and its relationship to cognition, real-world functioning, and functional capacity. Am J Psychiatry. 2006;163(3):426-432.

26. Citrome L, Weiden PJ, McEvoy JP, et al. Effectiveness of lurasidone in schizophrenia or schizoaffective patients switched from other antipsychotics: a 6-month, open-label, extension study. CNS Spectr. 2014; 19(4):330-339.

27. Stahl SM, Cucchiaro J, Simonelli D, Hsu J, Pikalov A, Loebel A. Effectiveness of lurasidone for patients with schizophrenia following 6 weeks of acute treatment with lurasidone, olanzapine, or placebo: a 6-month, open-label, extension study. J Clin Psychiatry. 2013;74(5):507-515.

28. Tandon R, Loebel A, Phillips D, et al. EPA-1722 - A double-blind, placebo-controlled, randomized withdrawal study of lurasidone for the maintenance of efficacy in patients with schizophrenia [abstract]. Eur Psychiatry. 2014;29(Supplement 1):S372.

29. Loebel A. Dose escalation in early nonresponders to $80 \mathrm{mg} /$ day of lurasidone: The Optimize study. Presented at the annual meeting of the American College of Neuropsychopharmacology; Phoenix, 2014.

30. Sunovion ProFile ${ }^{\mathrm{TM}}$ [webpage on the Internet]. Metabolic parameters: metabolic parameters evaluated in multiple bipolar depression studies for 6 weeks and 12 weeks. Marlborough, MA: Sunovion Pharmaceuticals Inc.; 2015. Available from: https://www.sunovionprofile.com/sp/ latuda-bp/metabolic-parameters.html. Accessed March 25, 2015.

31. Loebel AD, Siu CO, Cucchiaro JB, Pikalov AA, Harvey PD. Daytime sleepiness associated with lurasidone and quetiapine XR: results from a randomized double-blind, placebo-controlled trial in patients with schizophrenia. CNS Spectr. 2014;19(2):197-205.

32. Leucht S, Cipriani A, Spineli L, et al. Comparative efficacy and tolerability of 15 antipsychotic drugs in schizophrenia: a multiple-treatments meta-analysis. Lancet. 2013;382(9896):951-962.
Neuropsychiatric Disease and Treatment

\section{Publish your work in this journal}

Neuropsychiatric Disease and Treatment is an international, peerreviewed journal of clinical therapeutics and pharmacology focusing on concise rapid reporting of clinical or pre-clinical studies on a range of neuropsychiatric and neurological disorders. This journa is indexed on PubMed Central, the 'PsycINFO' database and CAS,

\section{Dovepress}

and is the official journal of The International Neuropsychiatric Association (INA). The manuscript management system is completely online and includes a very quick and fair peer-review system, which is all easy to use. Visit http://www.dovepress.com/testimonials.php to read real quotes from published authors. 